\title{
SEED SOAKING WITH SODIUM SILICATE PRIMES SALT TOLERANCE IN RICE (ORYZA SATIVA L.) SEEDLINGS WITHOUT ANY NEGATIVE EFFECT ON GROWTH
}

\author{
XU, C. C. ${ }^{1,2 \#}-$ ZHANG, Q. R. ${ }^{3 \#}-$ HU, L. ${ }^{4}-$ WANG, R. M. ${ }^{1}-$ SHI, Q. ${ }^{2}-$ CHEN, J. $^{1}-$ SONG, Y. Y. ${ }^{1}-$ \\ CHEN, D. M. ${ }^{1}-$ ZENG, R. S. ${ }^{1 *}-$ SUN, Z. X. ${ }^{1 *}$ \\ ${ }^{1}$ Key Laboratory of Ministry of Education for Genetics, Breeding and Multiple Utilization of \\ Crops, College of Agriculture, Fujian Agriculture and Forestry University \\ Fuzhou 350002, China \\ ${ }^{2}$ College of Life Sciences, Fujian Agriculture and Forestry University, Fuzhou 350002, China \\ ${ }^{3}$ Crop Research Institute, Fujian Academy of Agricultural Sciences, Fuzhou 350013, China \\ ${ }^{4}$ Key Laboratory of Beibu Gulf Environment Change and Resources Utilization of Ministry of \\ Education, Nanning Normal University, Nanning 530001, China \\ ${ }^{\#}$ These authors equally contributed to the study. \\ *Corresponding authors \\ e-mail: szx@fafu.edu.cn (Sun, Z.X.), rszeng@fafu.edu.cn (Zeng, R. S.) \\ phone: +86-184-5263-6956; fax:+86-591-8378-9483) \\ (Received $27^{\text {th }}$ Feb 2020; accepted $2^{\text {nd }}$ Jul 2020)
}

\begin{abstract}
Rice is one of the most important cereal crops and is susceptible to salinity stress. To enhance biotic and abiotic stress tolerance in crops, the application of silicon ( $\mathrm{Si}$ ) during seedling culture and seed priming are two effective approaches. However, whether seed priming with silicon can enhance salinity stress tolerance in rice seedlings, and what the optimal concentration of Si treatment is largely unclear. In this study, rice seeds were pretreated with sodium silicate, and the hydroponically grown rice seedlings were exposed to sodium chloride. Our results show that seed soaking with Si can significantly improve the growth of rice seedlings under salinity-stress, as evidenced by enhanced fresh weight, dry weight, leaf relative water content, photosynthetic pigment level, soluble protein content, as well as the activities of POD and SOD enzymes. Moreover, Si-pretreated seeds showed accelerated seed germination, increased seedling height and reduced root length. Furthermore, qRT-PCR analysis showed that seed soaking with Si induced the transcription of genes encoding $\mathrm{Na}^{+} / \mathrm{H}^{+}$exchangers and $\mathrm{H}^{+}$-pyrophosphatase. Our results imply that seed priming with $\mathrm{Si}$ enhances seedling tolerance to salinity stress without negative effect on growth and it can be used as an effective strategy.
\end{abstract}

Keywords: $\mathrm{Na}_{2} \mathrm{SiO}_{3}$, priming, salinity stress, OsNHX1, OsVPI

\section{Introduction}

Rice (Oryza sativa L.) is one of the most important food crops in the world (Higham and $\mathrm{Lu}, 1998$ ). It feeds more than one half of the global population (Mather et al., 2007). However, in many regions of rice production, the yield is markedly reduced due to salinity (Tuteja, 2007; Sakadevan and Nguyen, 2010). The cultivation of salt-tolerant varieties and efforts to reduce soil salinity are two common approaches to minimize the effects of salinity stress on crops (Ganie et al., 2019). However, salt-tolerant rice varieties are not readily available or their yield is low, and reducing soil salinity is costly.

Seed priming has been shown to be a simple, low cost and effective approach to enhance seed germination, early seedling growth and yield under stress conditions 
(Hameed et al., 2013). Priming seeds with certain bioactive chemicals such as hormones and antioxidants has been reported to enhance crop performance under harsh conditions (Guntzer et al., 2012; Hameed et al., 2013; Etesami, 2018). For example, seed priming with salicylic acid (SA) improved seedling emergence, root, shoot and length, seedling fresh and dry weight both at optimal and low temperatures (Farooq et al., 2008).

Silicon ( $\mathrm{Si}$ ) is the second most abundant element found in the soil, next to oxygen (Sahebi et al., 2015). As a fertilizer, biostimulant or plant protectant, Si plays a pivotal role in plant growth and productivity, especially in stress regimes (Savvas and Ntatsi, 2015). Over the last two decades, numerous studies have demonstrated that the application of Si can enhance plant resistance to biotic stresses caused by microbial pathogens and insect herbivores, as well as abiotic stresses, such as drought, waterlogging, freezing, high temperature, and UV, as well as salinity, nutrient deficiencies, and metal toxicity (Guntzer et al., 2012; Ma and Takahashi, 2002; Balakhnina and Borkowska, 2013; Rizwan et al., 2015). Si application can also enhance maize seed germination, seedling growth (Guan et al., 2009) and tolerance to alkaline stress (Abdel Latef and Tran, 2016). Hameed and Sheikh (Hameed et al., 2013) reported that priming wheat seeds with sodium silicate improved seed germination and seedling growth under water-deficit stress.

Rice is known as a Si accumulator, and therefore is a good model crop to investigate the impacts of $\mathrm{Si}$ on plant performance and tolerance to environmental stresses (Ma et al., 2006). In the present study, we determined the impacts of seed soaking with different concentration gradients of $\mathrm{Si}$ on growth and salinity stress tolerance of rice plants. After discovering the optimal concentration of Si treatment, we examined the possible effects of Si pre-treatment on growth traits, including seedling biomass, root length and shoot height, as well as physiological traits such as levels of chlorophyll (Chl) a and b, carotenoids, malondialdehyde (MDA), proline and the activities of antioxidant enzymes of rice seedlings grown in nutrient solution with different concentrations of sodium chloride.

\section{Materials and Methods}

\section{Seeds induction and germination}

The experiment was performed in the Experimental Farm of Fujian Agriculture and Forestry University, Fuzhou, China $\left(119^{\circ} 54^{\prime} \mathrm{E}, 26^{\circ} 05^{\prime} \mathrm{N}\right)$ in May 2018 using a salinity stress-sensitive rice (Oryza sativa L. cv. Shishoubaimao). Rice seeds were sterilized with $1 \%$ sodium hypochlorite solution for $10 \mathrm{~min}$ and rinsed with sterile distilled water. The sterilized seeds were divided into six groups: the first group (Control) was treated with distilled water, and the other five groups were treated with $2.5,5.0,10.0,15,20 \mathrm{mM}$ sodium metasilicate $\left(\mathrm{Na}_{2} \mathrm{SiO}_{3} .9 \mathrm{H}_{2} \mathrm{O}\right)$ solutions for $48 \mathrm{~h}$, separately. After treating with sodium silicate, the seeds were germinated on wet cotton cloth for $5 \mathrm{~d}$. The germination potential of the primed and non-primed rice seeds was examined using the seed test of the Association of Official Seed Analysts (AOSA). To test seed germination and seedling vigor under salinity stress, 20 seeds of each treatment with four replicates were germinated in petri dishes $(12 \mathrm{~cm}$ in diameter $)$ at $25^{\circ} \mathrm{C}$. A seed was considered to have germinated when a 2-3 mm long coleoptile and radicle was formed. Seed germination was counted twice a day at different time intervals $(24,48 \mathrm{~h})$ starting from the first day and terminated when maximum germination was attained. 


\section{Rice cultivation and salt stress treatment}

After $5 \mathrm{~d}$ of germination, the seedlings were placed in plastic pot with normal nutrient solution for another $7 \mathrm{~d}$. Then the seedlings were transplanted in nutrient solution with sodium chloride, $\mathrm{NaCl}(120 \mathrm{mM})$ for $7 \mathrm{~d}$. The degree of leaf damage was determined by the percentage of yellow area of leaf: If the whole leaf is green, we count it as 0 ; if the percentage of yellow area of the whole leaf $\leq 25 \%$, we count it as 0.25 ; if the percentage of yellow area of the whole leaf between $25 \%$ and $50 \%$, we count it as 0.5 , if the percentage of yellow area of the whole leaf between $50 \%$ and $75 \%$, we count it as 0.75 , if the percentage of yellow area of the whole leaf $\geq 75 \%$, we count it as 1 . This criteria are based on Renganayaki et al. (2002).

\section{Effect on seedling growth}

For growth response, rice seedlings were allowed to continue to grow after collecting the data for germination. Fifteen days old seedlings were then harvested for comparison of growth under nutrient solution after seed priming treatments. Root and shoot lengths were then quantified. The fresh weight of rice seedlings was estimated after washing with deionized water, and blotting on paper towels. Their dry biomass was weighed after oven drying at $80^{\circ} \mathrm{C}$ to constant weight. The dried tissues were stored in clean sealed glasses at room temperature for later analysis.

\section{Effect on water content under salinity stress and photosynthetic pigments}

Leaf relative water content (LRWC) was determined using the method described in Garíca-Mata and Lamattina, using the equation:

$$
\text { LRWC }(\%)=\frac{\text { Fresh weight }- \text { Dry weight }}{\text { Turgid weight }- \text { Dry weight }} * 100
$$

The contents of chlorophyll a, b and carotenoid in fresh leaves were assessed spectrophotometrically as described previously (Lichtenthaler and Wellburn, 1983). The fully expanded young leaves $(0.05 \mathrm{~g})$ of 15 -day-old plants were treated with $120 \mathrm{mM}$ $\mathrm{NaCl}$ for 24 and $48 \mathrm{~h}$. The leaves were used for pigment extraction in $80 \%$ acetone. The extract of pigments was measured versus a blank of pure $80 \%$ acetone at 663,644 , and

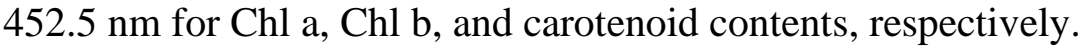

\section{Determination of soluble protein, proline and MDA content}

Total soluble protein content in leaves of rice after 7 days under salinity stress was measured as described previously (Gao, 2006). Total soluble protein content in leaves of rice after 7 days under salinity stress was measured according to the method described by Bates et al (1973). Malondialdehyde (MDA) is the main product of membrane lipid peroxidation when plants are under stress, and its content represents the degree of cell membrane damage. Malondialdehyde content was determined according to the thiobarbituric acid (TBA) reaction as described by Draper et al. (1993). Fresh leaf sample $(0.5 \mathrm{~g})$ was homogenized with $5 \%$ trichloroacetic acid and centrifuged at 4,000 $\mathrm{g}$ for $10 \mathrm{~min}$. Two milliliters of extract were mixed with $2 \mathrm{~mL}$ of $0.6 \%$ TBA, and the mixture was placed in a boiling water bath for $10 \mathrm{~min}$. Subsequently, the absorbances were read at 532, 600, and $450 \mathrm{~nm}$, separately. The MDA content was calculated using the formula: 


\section{Assays for antioxidant enzyme activities}

Samples were extracted from the fresh leaves as described previously (Mukherjee and Choudhuri, 1983). The fresh leaves $(0.5 \mathrm{~g})$ were frozen in liquid nitrogen and ground in $10 \mathrm{~mL}$ of $100 \mathrm{mM}$ phosphate buffer $\left(\mathrm{KH}_{2} \mathrm{PO}_{4} / \mathrm{K}_{2} \mathrm{HPO}_{4}\right) \mathrm{pH} 7.0$, containing $0.1 \mathrm{mM}$ $\mathrm{Na}_{2}$ EDTA and $0.1 \mathrm{~g}$ of polyvinylpyrrolidone (PVP). The homogenate was centrifuged at $15,000 \mathrm{~g}$ at $4^{\circ} \mathrm{C}$ for $10 \mathrm{~min}$. Subsequently, the supernatant was stored at $4^{\circ} \mathrm{C}$ until use for assays of superoxide dismutase (SOD) and peroxidase (POD). SOD activities were assayed as described previously (Giannopolitis and Ries, 1977). POD and SOD are important antioxidant components of plant tolerance to salinity stress (Sudhakar et al., 2001).

\section{RNA extraction and cDNA synthesis}

Fresh leaf samples $(100 \mathrm{mg})$ of rice plant were collected after $0,1,3$ and 5 days of treatment with $120 \mathrm{mM} \mathrm{NaCl}$, and immediately transferred to liquid nitrogen and stored at $-80^{\circ} \mathrm{C}$. Total RNAs were isolated from flash-frozen tissues using the Eastep Super Total RNA Extraction Kit (Promega, Madison, WI, United States) and quantified by measuring the absorbance at 280 and $260 \mathrm{~nm}$. Then the equal RNAs from three replicates were reverse-transcribed with a GoScript Reverse Transcription System (Promega), which were used for qRT-PCR analysis.

\section{Quantitative real-time PCR ( $q$ RT-PCR) analysis}

To validate the gene expression, quantitative real-time PCR (qRT-PCR) was performed on an Applied Biosystems StepOne Plus Real-Time PCR System in a $10 \mu \mathrm{L}$ reaction volume consisting of $5 \mu \mathrm{L}$ of $2 \times$ SYBR GoTaq qPCR Master Mix (Promega), $0.4 \mu \mathrm{L}$ of each gene-specific primers $(10 \mu \mathrm{M}), 1 \mu \mathrm{L}$ cDNA equivalent to $50 \mathrm{ng}$ total RNA and sterilized water to reach the final volume. PCR conditions were set as: 1 cycle of $95^{\circ} \mathrm{C}$ for $10 \mathrm{~min} ; 40$ cycles of $95^{\circ} \mathrm{C}$ for $15 \mathrm{~s}, 55^{\circ} \mathrm{C}$ for $30 \mathrm{~s}$ and $72^{\circ} \mathrm{C}$ for $30 \mathrm{~s}$. The reference gene actin (TIGR ID Os03g50885) was used as the internal control. A dissociation curve analysis program was performed to check the homogeneity of the PCR product. Relative standard curves of actin and target genes were generated by using 10- fold serial dilutions cDNA to calculate the amplification efficiencies of primers. The relative mRNA levels were normalized against actin using the $2^{-\Delta \Delta} \mathrm{Ct}$ method (Livak and Schmittgen, 2001). Three independent biological repeats were performed, each sample had two technical replicates, and a calibrator sample was used to make comparisons between different plates. All the primers were listed on Table 1. All designed primers were synthesized at BioSune Biotechnology Co., Ltd. (Shanghai, China).

\section{Statistical analysis}

Data were statistically analyzed by the analysis of variance (ANOVA) with SPSS software, using Dunnett's multiple range test at the 0.05 level of significance $(p<0.05)$. Data represented in the Tables and Figures are means \pm standard error of at least three independent replicates. 
Table 1. Primers used for qPCR analysis in this study

\begin{tabular}{c|c|c}
\hline Gene & Forward primer $\left(5^{\circ}\right.$ to $\left.3^{\circ}\right)$ & Reverse primer $\left(5^{\circ}\right.$ to $\left.3^{\circ}\right)$ \\
\hline OsActin & TGGACAGGTTATCACCATTGGT & CCGCAGCTTCCATTCCTATG \\
OsASIE1 & TGGTCTGATTTGGTAGCC & TCCAAGAACTGGCAGACGA \\
OsNHX1 & CCTGGAGACAGCAAGTTGT & CTCTGCTCGGTTGGTGATC \\
OsVP1 & AAGATGACCCAAGAAACCCA & GGTACAGCATAGGAGTGAAT \\
\hline
\end{tabular}

\section{Results}

\section{Seed soaking with Si enhances tolerance of rice against salinity stress}

To examine the effect of Si pretreatment on rice salinity stress, the rice seeds were soaked with distilled water (control group) or sodium silicate and then the rice seedlings were exposed to salinity stress. $\mathrm{NaCl}(120 \mathrm{mM})$ treatment led to severe damage for plant growth (Fig. 1A). However, compared with the control and $2.5 \mathrm{mM}$ group, rice seed soaking with $\mathrm{Si}$ at $\geq 5 \mathrm{mM}(5,10,15$ and $20 \mathrm{mM})$ concentrations significantly decreased the degree of leaf damage by $\mathrm{NaCl}$ (Fig. $1 A$ and $1 B$ ). The Si-soaked seedlings showed more green leaves and vital stems (Fig. 1A).
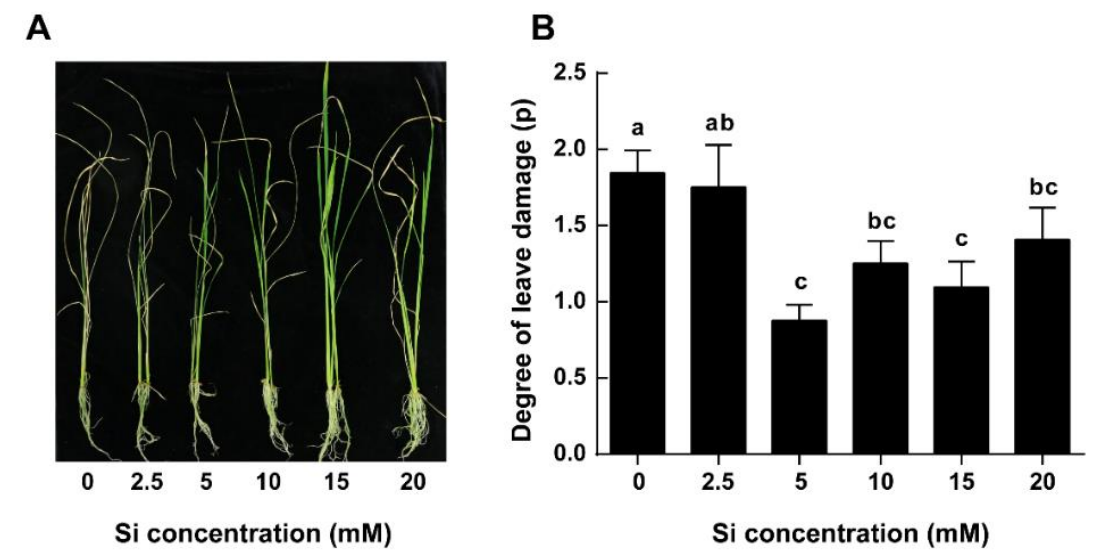

Figure 1. Effect of seed soaking with sodium silicate on salinity tolerance of rice seedlings. Phenotypes (A) and degree of leaf damage (B) of rice seedlings treated with $120 \mathrm{mM} \mathrm{NaCl} \mathrm{for}$

$3 d$ after seed soaking with different concentrations of sodium silicate for $48 \mathrm{~h}$. Data are expressed as means $\pm S E(n=6)$. Different letters above the bars indicate significant differences among treatments ( $P<0.05$ according to Dunnett's multiple range test)

\section{Seed soaking with Si improved seed germination and seedling growth}

After seed soaking with $\mathrm{Si}$ solutions at $\geq 5 \mathrm{mM}$ the seed germination rates were significantly higher $24 \mathrm{~h}$ after incubation relative to control (Fig. 2A). Seeds soaked in a solution with $20 \mathrm{mM} \mathrm{Si}$ showed the highest germination rate. However, there was no significant difference between control and five treatments at $48 \mathrm{~h}$ after incubation (Fig. 2A), implying that seed soaking with Si only accelerated the seed germination, but did not improve the final germination rate.

Seven days after transplantation seed soaking with Si solutions at $\geq 10 \mathrm{mM}$ had shorter root lengths (Fig. 2B), but had longer shoot lengths, although only the $15 \mathrm{mM}$ Si treatment showed significant effect compared to the control (Fig. 2C). Based on the results from 
Fig. 1 and Fig. 2, 10 and $15 \mathrm{mM}$ concentrations of sodium silicate were chosen as the optimal concentrations for the following experiments.

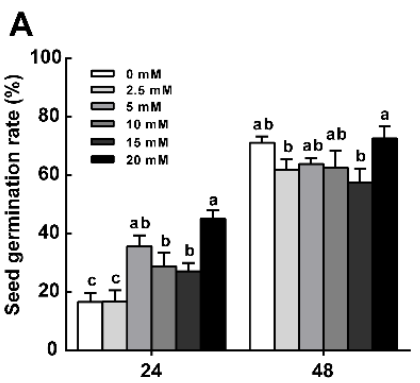

Germination time (h)

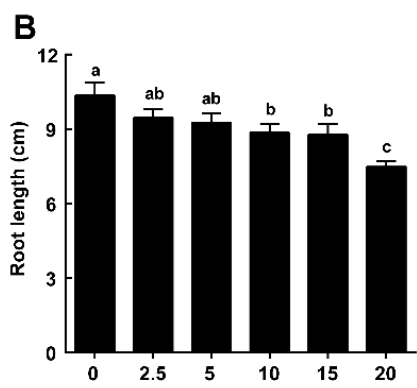

Si concentration $(\mathrm{mM})$

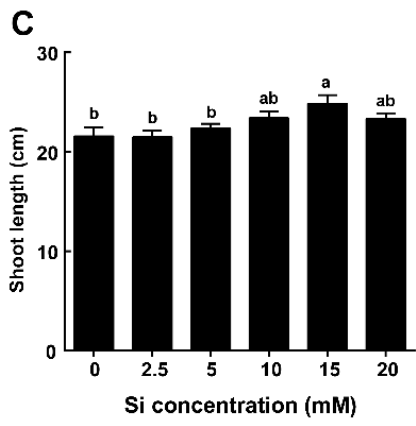

Figure 2. Effect of seed soaking with sodium silicate on seed germination (A) and root length $(B)$ and shoot length $(C)$ of rice seedlings treated with $\mathrm{NaCl}$. After seed soaking with different concentrations of sodium silicate for $48 \mathrm{~h}$, the seeds were germinated for $2 d$ and rice plants were grown for 7 days in nutrient solution containing $120 \mathrm{mM} \mathrm{NaCl}$. Data are expressed as means $\pm S E(n=6)$. Different letters above the bars indicate significant differences among treatments $(P<0.05$ according to Dunnett's multiple range test)

\section{Seed soaking with Si increases rice biomass, leaf relative water content and photosynthetic pigments}

After seed pretreatment with Si for $48 \mathrm{~h}$, fresh weight, dry weight and leaf relative water content (LRWC) of rice seedlings were measured 1, 3, 5 and 7 days after $\mathrm{NaCl}$ treatment. Compared with control group, seed pretreatment with $\mathrm{Si}$ enhanced the fresh weight on day 3 and day 7 (Fig. 3A) and dry weight on day 3-7 (Fig. 3B). On day 7, seed pretreatment with $15 \mathrm{mM} \mathrm{Si}$ increased leaf relative water content (LRWC) (Fig. 3C).

In order to understand physiological mechanism of enhanced salt tolerance of rice seedlings by seed soaking with sodium silicate, we measured the contents of chlorophyll a, b and carotenoid in fresh leaves of rice seedlings. We found that prior treatment of seeds with 10 or $15 \mathrm{mM} \mathrm{Si}$ significantly increased contents of Chl a and b at $24 \mathrm{~h}$ after salinity stress (Fig. $3 D$ and $3 E$ ). Contents of Chl a were also increased by seed treatment with $15 \mathrm{mM} \mathrm{Si}$ for $48 \mathrm{~h}$ (Fig. 3D). Prior treatment of seeds with 10 or $15 \mathrm{mM}$ $\mathrm{Si}$ significantly increased contents of carotenoid $48 \mathrm{~h}$ after exposure to salinity stress (Fig. 3F).

\section{Seed soaking with Si increased soluble protein and decreased proline and MDA}

The soluble protein content in rice leaves was determined 7 days after exposure to salt stress. Si treatments at $10 \mathrm{mM}$ and $15 \mathrm{mM}$ led to $60 \%$ and $80 \%$ increase in soluble protein compared with Si-untreated control (Fig. 4A). The content of proline in rice plants was significantly reduced by $15 \mathrm{mM}$ Si pretreatment 5 days after exposure to salt stress (Fig. 4B). Our results showed that in the rice leaves content of MDA significantly accumulated 3 days after exposure to salt stress. However, seed soaking with $10 \mathrm{mM}$ and $15 \mathrm{mM}$ Si led to $38 \%$ and $37 \%$ reduction in MDA contents $3 \mathrm{~d}$ after salinity stress, and $43 \%$ and $55 \%$ reduction $5 \mathrm{~d}$ after salinity stress, respectively (Fig. $4 \mathrm{C}$ ). 
A
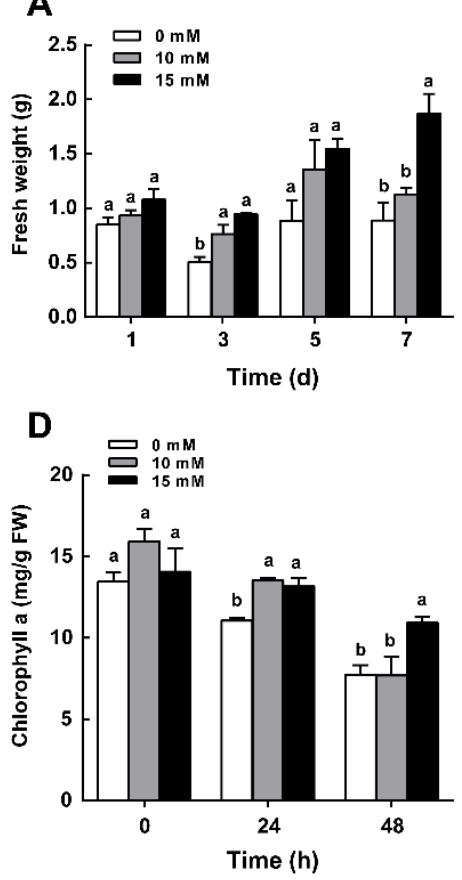

B

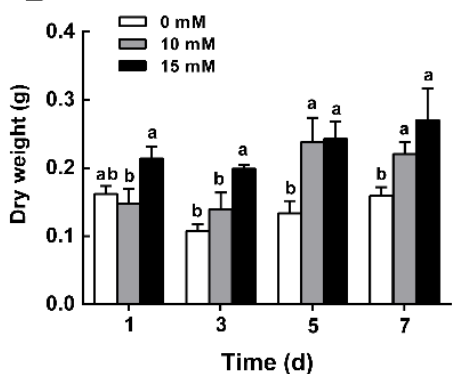

$\mathrm{E}$

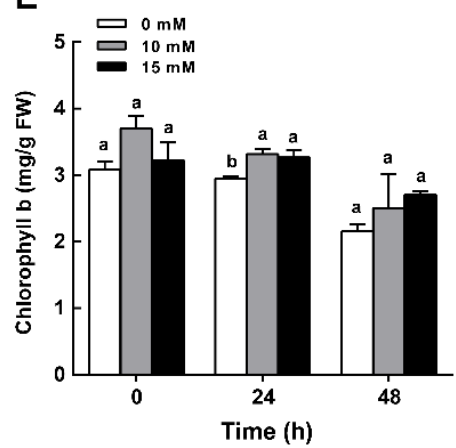

C

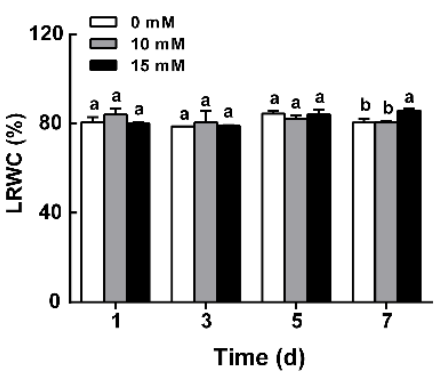

$\mathbf{F}$

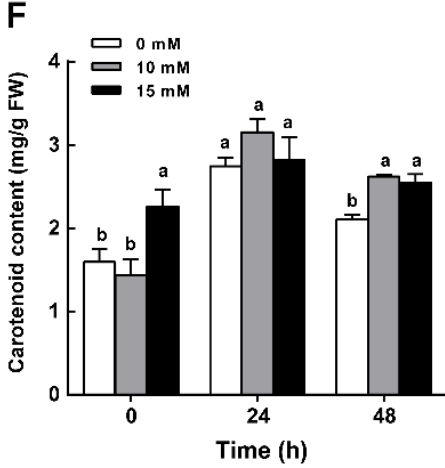

Figure 3. Effect of seed soaking with sodium silicate on fresh weight (A), dry weight (B), LRWC $(C)$, chlorophyll a $(D)$, chlorophyll $b(E)$ and carotenoid content $(F)$ of rice seedlings treated with $\mathrm{NaCl}$. Rice seedlings were cultivated in nutrient solution containing $120 \mathrm{mM} \mathrm{NaCl}$. Data are expressed as means $\pm S E(n=3-5)$. Different letters above the bars indicate significant differences among treatments $(P<0.05$ according to Dunnett's multiple range test)
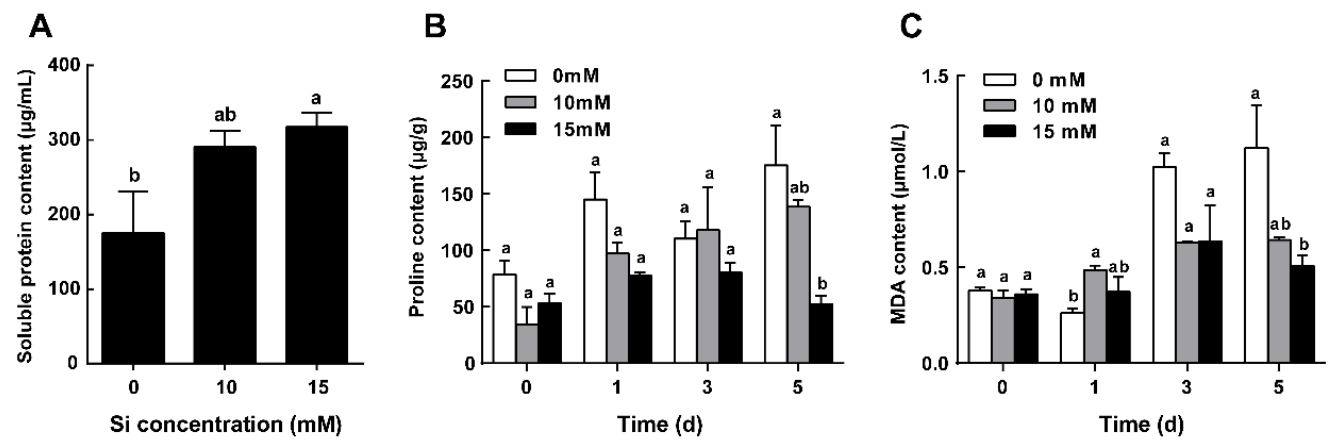

Figure 4. Effect of seed soaking with sodium silicate on soluble protein $(A)$, proline content $(B)$ and MDA content $(\mathrm{C})$ in the leaves of rice seedlings treated with $\mathrm{NaCl}$. Rice seedlings were cultivated in nutrient solution containing $120 \mathrm{mM} \mathrm{NaCl}$. Data are expressed as means $\pm S E$ $(n=3-5)$. Different letters above the bars indicate significant differences among treatments $(P<0.05$ according to Dunnett's multiple range test $)$

\section{Seed soaking with Si enhanced antioxidant enzymes}

Our results showed that seed soaking with $15 \mathrm{mM}$ Si significantly enhanced activities of POD and SOD. Seed soaking with $15 \mathrm{mM}$ Si increased POD by about 50\% (Fig. 5A) and SOD by $20 \%$ relative to the control (Fig. 5B). 

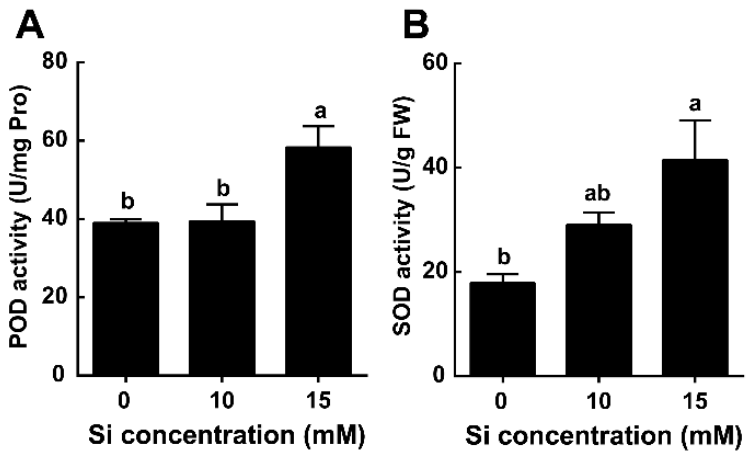

Figure 5. Effect of seed soaking with sodium silicate on the activities of peroxidase (POD) (A) and superoxide dismutase $(S O D)(B)$ in the rice leaves under salt stress for 7 days. Data are means $\pm S E(n=5)$. Different letters above the bars indicate significant differences among treatments $(P<0.05$ according to Dunnett's multiple range test)

\section{Seed soaking with Si induced transcription of salt tolerance-related genes}

We want to know whether seed soaking with Si enhance salinity stress tolerance by inducing the transcription of genes encoding OSASIE1, OsNHXI and OsVP1. Real-time PCR analysis showed that compared with control, the OSASIEl gene expression was upregulated in rice plants pretreated with $10 \mathrm{mM} \mathrm{Si} 1$ days after exposure to salt stress and $15 \mathrm{mM} \mathrm{Si} \mathrm{1,} 3$ and 5 days after salt stress (Fig. 6A). The expression of $O s N H X 1$ was significantly enhanced in rice plants pretreated with $15 \mathrm{mM} \mathrm{Si} 3$ days after exposure to salt stress (Fig. 6B). The expression of $O s V P 1$ was up-regulated in rice plants pretreated with $15 \mathrm{mM}$ Si 3 and 5 days after exposure to salt stress (Fig. 6C).
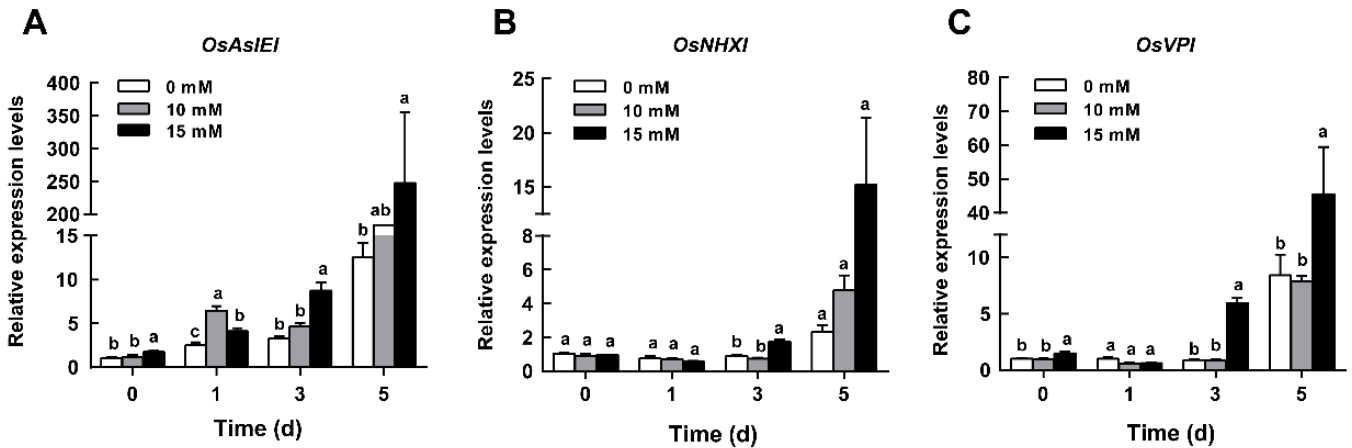

Figure 6. Effect of seed soaking with sodium silicate on the expression of OsASIE1 (A), (B)

OsNHX1 (B), OsVP1 (C) in the rice leaves under salt stress for 0, 1, 3, 5 days. Data are expressed as means $\pm S E(n=5)$. Different letters above bars indicate significant differences among treatments $(P<0.05$ according to Dunnett's multiple range test)

\section{Discussion}

Soil salinity is a major abiotic stress that can lead to a substantial decrease in crop yields (Rengasamy, 2010). Rice plants are particularly vulnerable to salt stress and therefore there has been great interest in improving rice resistance to salinity. Si plays an important role in conferring plant resistance to a wide range of biotic and abiotic stresses (Reynolds et al., 2016), including salinity, as has been shown for crops such as wheat, 
maize, barley, cucumber, etc (Liang et al., 1996; Zhu et al., 2004; Tuna et al., 2008). We show here that soaking seeds in Si solutions for a short term $(48 \mathrm{~h})$ can enhance tolerance to salinity stress and lead to several positive consequences for rice plant performance. The degree of stress-induced leaf damage was also significantly reduced in rice plants grown from Si-primed seeds as compared to plants from untreated seeds. The reduction in photosynthetic pigments of rice leaves after $\mathrm{NaCl}$ treatment found in this study (Fig. 3D, E, F) supports the findings of Kariola et al. (2005). The decrease in chlorophyll content under salinity stress may be due to increased oxidative stress that causes injury to chloroplast structure and an increase in the activity of chlorophyllase, which is responsible for the chlorophyll degradation (Tarja et al., 2005; Abdel Latef and He, 2014). Si treatment increased the chlorophyll and carotenoid contents in rice plants exposed to salinity stress, which could result in the increase in seedling fresh and dry weight, as well as the increase in green pigments per unit area. It must have also safeguarded the chlorophyll from ROS by reinforcing the carotenoid levels.

In general, increased resistance occurs with simultaneous growth inhibition. We found the opposite; Si treatment enhanced the speed of seed germination, but did not significantly affect final germination success. It also increased seedling height compared with untreated group (Fig. 2C) (Hameed et al., 2013; Etesami, 2018). These results imply that priming of salt tolerance by seed soaking with sodium silicate does not affect rice performance.

Salt tolerance of plants may be reflected in a number of parameters, including the contents of chlorophyll a and b, carotenoids, malondialdehyde and proline, as well as the activities of antioxidant enzymes. In maize plants, it has been shown that the content of soluble proteins increase under high alkaline pressure (Abdel Latef, 2010; Abd-Alla et al., 2014; Mohsenian and Roosta, 2015). Here, the increase in soluble protein content of rice plants under salinity stress was accompanied by a marked reduction in growth. This suggests that under salinity stress, rice plants divert much of the synthesized proteins from growth to resistance responses. The highest soluble protein level was observed in the rice seedlings that developed from seeds soaked in $15 \mathrm{mM} \mathrm{Si}$. It is known that proline can serve as an important osmotic adjustment substance in plant cells (Silveira et al., 2003) and proline content can be used as a physiological index of a plant's resistance to stress tolerance (Toyooka et al., 2009). The accumulation of proline was reduced in the Si-pretreated seedlings, which suggests that seed priming with $\mathrm{Si}$ could protect cells by keeping the accumulation of proline to an optimum level (Fig. 4B).

Under salinity stress, the increase of reactive oxygen species leads to lipid peroxidation in cell membranes. Malondialdehyde is the main product of membrane lipid peroxidation, and the levels at which it is produced therefore represents the degree of cell membrane damage (Silveira et al., 2003). We found that malondialdehyde levels increased in rice leaves under salinity stress, but this increase was significantly mitigated by Si treatment of the seeds (Fig. 4C). Furthermore, seed priming with $\mathrm{Si}$ also resulted in a significant increase in SOD and POD activities in rice seedlings exposed to salinity stress relative to plant treated with $\mathrm{NaCl}$ alone. These results indicate that $\mathrm{Si}$ enhances antioxidant activity that protects plants against salinity induced oxidative damage (Fig. 5).

Certain plant membrane transporters particularly $\mathrm{Na}^{+}$and $\mathrm{K}^{+}$transporters are involved in plant resistance to salt stress. OsSOS1 $\left(\mathrm{Na}^{+} / \mathrm{H}^{+}\right.$antiporters) (Kumar and Sinha, 2013; Amin et al., 2016), OsCAXI $\left(\mathrm{H}^{+} / \mathrm{Ca}^{+}\right.$antiporter) (Kumar and Sinha, 2013), OsAKT1 $\left(\mathrm{K}^{+}\right.$ inward-rectifying channel) (Yang et al., 2014), OsKCO1 ( $\mathrm{K}^{+}$outward-rectifying channel) (Kumar and Sinha, 2013), OsCLC1 ( $\mathrm{Cl}^{-}$channel) (Diédhiou and Golldack, 2006), 
OsNRT1;2 (nitrate transporter) (Yang et al., 2014), and OsTPC1 $\left(\mathrm{Ca}^{2+}\right.$ permeable channel) (Kurusu et al., 2012) have all been shown to play a role in rice resistance to salt stress. In our study we found that seed soaking with $\mathrm{Si}$ induced transcription of genes encoding $\mathrm{Na}^{+} / \mathrm{H}^{+}$exchangers (OsNHXI) and $\mathrm{H}^{+}$-pyrophosphatase (OsVPl) (Fig. 6). OSASIE1 may participate in abiotic stress response by regulating the expression of downstream genes with DRE and GCC box binding. Overexpression of OSASIE1 improves rice tolerance to salt stress (Wu et al., 2011). In this study, OsNHX1 showed a quick response to salinity stress in $10 \mathrm{Mm}$ treatment but not change in the following days due to the reason that $N H X$ genes increase salt tolerance by reducing $\mathrm{Na}^{+}$contents in the leaves. This is in accordance with Liu et al. (2010) who found that the overexpression of $O s N H X 1$ and $O s V P 1$ in tonoplasts improved rice tolerance to salt and drought.

\section{Conclusion}

In conclusion, seed priming with $\mathrm{Si}$ significantly improved rice tolerance to salinity without any negative effect on growth. This treatment may therefore serve as a highly effective strategy to improve rice tolerance to salinity stress. The detailed molecular mechanism should be further investigated.

Acknowledgements. We thank Professor Ted Turlings for revising the manuscript. This work was supported by the Talent Program of Fujian Agriculture and Forestry University (KXJQ19009), National College Student Innovation Program, China (202010389013), Natural Science Fund project of Fujian Province (2020J01130966), National Natural Science Foundation of China (31870361), and Fujian Provincial Excellent Youth Science Foundation (2017J06010).

\section{REFERENCES}

[1] Abd-Alla, M. H., El-Enany, A. W. E., Nafady, N. A., Khalaf, D. M., Morsy, F. M. (2014): Synergistic interaction of Rhizobium leguminosarum bv. viciae and arbuscular mycorrhizal. ungi as a plant growth promoting biofertilizers for faba bean (Vicia faba L.) in alkaline soil. - Microbiol Res 169(1): 49-58.

[2] Abdel Latef, A. (2010): Changes of antioxidative enzymes in salinity tolerance among different wheat cultivars. - Cereal Res Commun 38(1): 43-55.

[3] Abdel Latef, A. A. H., He, C. X. (2014): Does inoculation with glomus mosseae improve salt tolerance in pepper plants? - J Plant Growth Regul 33(3): 644-653.

[4] Abdel Latef, A. A., Tran, L.-S. P. (2016): Impacts of priming with silicon on the growth and tolerance of maize plants to alkaline stress. - Front Plant Sci 7: 243.

[5] Amin, U., Biswas, S., Elias, S. M., Razzaque, S., Haque, T., Malo, R., Seraj, Z. I. (2016): Enhanced salt tolerance conferred by the complete $2.3 \mathrm{~kb}$ cDNA of the rice vacuolar $\mathrm{Na}^{+} / \mathrm{H}^{+}$ antiporter gene compared to $1.9 \mathrm{~kb}$ coding region with $5^{\prime}$ UTR in transgenic lines of rice. - Front Plant Sci 7: 14.

[6] Balakhnina, T., Borkowska, A. (2013): Effects of silicon on plant resistance to environmental stresses. - Int Agrophys 27(2): 225-232.

[7] Bates, L. S., Waldren, R. P., Teare, I. (1973): Rapid determination of free proline for waterstress studies. - Plant Soil 39(1): 205-207.

[8] Diédhiou, C., Golldack, D. (2006): Salt-dependent regulation of chloride channel transcripts in rice. - Plant Sci 170(4): 793-800.

[9] Draper, H. H., Squires, E. J., Mahmoodi, H., Wu, J., Agarwal, S., Hadley, M. (1993): A comparative evaluation of thiobarbituric acid methods for the determination of malondialdehyde in biological materials. - Free Radical Bio Med 15(4): 353-363. 
[10] Etesami, H. (2018): Can interaction between silicon and plant growth promoting rhizobacteria benefit in alleviating abiotic and biotic stresses in crop plants? - Agr Ecosyst Environ 253: 98-112.

[11] Farooq, M., Aziz, T., Basra, S. M. A., Cheema, M. A., Rehman, H. (2008): Chilling tolerance in hybrid maize induced by seed priming with salicylic acid. - J Agron Crop Sci 194(2): 161-168.

[12] Ganie, S. A., Molla, K. A., Henry, R. J., Bhat, K., Mondal, T. K. (2019): Advances in understanding salt tolerance in rice. - Theor Appl Genet 132(4): 851-870.

[13] Gao, J. (2006): Experimental guidance for plant physiology. - China Higher Education Press, Beijing (Chinese).

[14] Giannopolitis, C. N., Ries, S. K. (1977): Superoxide dismutases: I. Occurrence in higher plants. - Plant Physiol 59(2): 309-314.

[15] Guan, Y. J., Jin, H. U., Wang, X. J., Shao, C. X. (2009): Seed priming with chitosan improves maize germination and seedling growth in relation to physiological changes under low temperature stress. - J Zhejiang Univ 10(6): 427-433.

[16] Guntzer, F., Keller, C., Meunier, J.-D. (2012): Benefits of plant silicon for crops: a review. - Agron Sustain Dev 32(1): 201-213.

[17] Hameed, A., Sheikh, M. A., Jamil, A., Basra, S. M. A. (2013): Seed priming with sodium silicate enhances seed germination and seedling growth in wheat (Triticum aestivum L.) under water deficit stress induced by polyethylene glycol. - Pakistan J Life \& Social Sci 11(1): 19-24.

[18] Higham, C., Lu, L. D. (1998): The origins and dispersal of rice cultivation. - Antiquity 72(278): 867-877.

[19] Kariola, T., Brader, G., Li, J., Palva, E. T. (2005): Chlorophyllase 1, a damage control enzyme, affects the balance between defense pathways in plants. - Plant Cell 17(1): 282294.

[20] Kumar, K., Sinha, A. K. (2013): Overexpression of constitutively active mitogen activated protein kinase kinase 6 enhances tolerance to salt stress in rice. - Rice 6(1): 25.

[21] Kurusu, T., Hamada, H., Koyano, T., Kuchitsu, K. (2012): Intracellular localization and physiological function of a rice $\mathrm{Ca}^{2+}$-permeable channel OsTPC1. - Plant Signal \& Behav 7(11): 1428-1430.

[22] Liang, Y., Shen, Q., Shen, Z., Ma, T. (1996): Effects of silicon on salinity tolerance of two barley cultivars. - J Plant Nutr 19(1): 173-183.

[23] Lichtenthaler, H. K., Wellburn, A. R. (1983): Determinations of total carotenoids and chlorophylls a and b of leaf extracts in different solvents. - Biochem Soc Trans 11(5): 591592.

[24] Liu, S., Zheng, L., Xue, Y., Zhang, Q., Wang, L., Shou, H. (2010): Overexpression of $O s V P 1$ and $O S N H X 1$ increases tolerance to drought and salinity in rice. - J Plant Biol 53(6): 444-452.

[25] Livak, K. J., Schmittgen, T. D. (2001): Analysis of relative gene expression data using realtime quantitative PCR and the $2^{-\Delta \Delta C T}$ method. - Methods 25(4): 402-408.

[26] Ma, J. F., Takahashi, E. (2002): Soil, fertilizer, and plant silicon research in Japan. Elsevier Science B. V.

[27] Ma, J. F., Tamai, K., Yamaji, N., Mitani, N., Konishi, S., Katsuhara, M., Ishiguro, M., Murata, Y., Yano, M. (2006): A silicon transporter in rice. - Nature 440(7084): 688.

[28] Mather, K. A., Caicedo, A. L., Polato, N. R., Olsen, K. M., Susan, M. C., Purugganan, M. D. (2007): The extent of linkage disequilibrium in rice (Oryza sativa L.). - Genetics 177(4): 2223.

[29] Mohsenian, Y., Roosta, H. R. (2015): Effects of grafting on alkali stress in tomato plants: datura rootstock improve alkalinity tolerance of tomato plants. - J Plant Nutr 38(1): 51-72.

[30] Mukherjee, S., Choudhuri, M. (1983): Implications of water stress-induced changes in the levels of endogenous ascorbic acid and hydrogen peroxide in Vigna seedlings. - Physiol Plantarum 58(2): 166-170. 
[31] Renganayaki, K., Fritz, A. K., Sadasivam, S., Pammi, S., Harrington, S. E., Mccouch, S. R. (2002): Mapping and progress toward map-based cloning of brown planthopper biotype4 resistance gene introgressed from into cultivated rice. - Crop Sci 42(6): 2112.

[32] Rengasamy, P. (2010): Soil processes affecting crop production in salt-affected soils. Funct Plant Biol 37(7): 613-620.

[33] Reynolds, O. L., Padula, M. P., Zeng, R., Gurr, G. M. (2016): Silicon: potential to promote direct and indirect effects on plant defense against arthropod pests in agriculture. - Front Plant Sci 7: 744.

[34] Rizwan, M., Ali, S., Ibrahim, M., Farid, M., Adrees, M., Bharwana, S. A., Zia-Ur-Rehman, M., Qayyum, M. F., Abbas, F. (2015): Mechanisms of silicon-mediated alleviation of drought and salt stress in plants: a review. - Environ Sci Pollut R 22(20): 15416-15431.

[35] Sahebi, M., Hanafi, M. M., Siti, N. A. A., Rafii, M. Y., Azizi, P., Tengoua, F. F., Nurul, M. A. J., Shabanimofrad, M. (2015): Importance of silicon and mechanisms of biosilica formation in plants. - Biomed Res Int 2015: 396010.

[36] Sakadevan, K., Nguyen, M. L. (2010): Chapter two-extent, impact, and response to soil and water salinity in arid and semiarid regions. - Ad Agron 109(109): 55-74.

[37] Savvas, D., Ntatsi, G. (2015): Biostimulant activity of silicon in horticulture. - Sci Horticamsterdam 196: 66-81.

[38] Silveira, J. A. G., de Almeida Viégas, R., da Rocha, I. M. A., de Oliveira Monteiro Moreira, A. C., de Azevedo Moreira, R., Oliveira, J. T. A. (2003): Proline accumulation and glutamine synthetase activity are increased by salt-induced proteolysis in cashew leaves. J Plant Physiol 160(2): 115-123.

[39] Tarja, K., Günter, B., Jing, L., Tapio, P. E. (2005): Chlorophyllase 1, a damage control enzyme, affects the balance between defense pathways in plants. - Plant Cell 17: 282-294.

[40] Toyooka, K., Goto, Y., Asatsuma, S., Koizumi, M., Mitsui, T., Matsuoka, K. (2009): A mobile secretory vesicle cluster involved in mass transport from the golgi to the plant cell exterior. - Plant Cell 21(4): 1212-1229.

[41] Tuna, A. L., Kaya, C., Higgs, D., Murillo-Amador, B., Aydemir, S., Girgin, A. R. (2008): Silicon improves salinity tolerance in wheat plants. - Environ Exp Bot 62(1): 10-16.

[42] Tuteja, N. (2007): Mechanisms of high salinity tolerance in plants. - Methods in Enzymology 428: 419-438.

[43] Wu, H.-M., Huang, L.-Y., Pan, Y.-J., Jin, P., Fu, B.-Y. (2011): Function of gene OsASIE1 in response to abiotic stress in rice. - Acta Agro Sin 37(10): 1771-1778.

[44] Yang, T., Zhang, S., Hu, Y., Wu, F., Hu, Q., Chen, G., Cai, J., Wu, T., Moran, N., Yu, L. (2014): The role of a potassium transporter OSHAK5 in potassium acquisition and transport from roots to shoots in rice at low potassium supply levels. - Plant Physiol 166(2): 945959.

[45] Zhu, Z., Wei, G., Li, J., Qian, Q., Yu, J. (2004): Silicon alleviates salt stress and increases antioxidant enzymes activity in leaves of salt-stressed cucumber (Cucumis sativus L.). Plant Sci 167(3): 527-533. 